\title{
Influence of the Magnetic Device on Water Quality and Production of Melon
}

\author{
Anis Elaoud ${ }^{1,2^{*}}$, Nejib Turki ${ }^{1,3}$, Hamza Ben Amor ${ }^{1,3}$, Rim Jalel ${ }^{4}$ and Nahla Ben Salah ${ }^{5}$ \\ ${ }^{1}$ Laboratory of Natural Treatment Water, Water Research and Technologies Center -Borj Cedria, Tunisia \\ ${ }^{2}$ Higher School of Engineers Medjez Elbeb, Tunisia \\ ${ }^{3}$ University of Carthage, National Institute of Agronomic Tunisia \\ ${ }^{4}$ Higher Institute of Agronomy of Chott-Mariem, Tunisia \\ ${ }^{5}$ Laboratory of probabilities and statistic, Faculty of Sciences of Sfax, Tunisia \\ Accepted 24 Dec 2016, Available online 30 Dec 2016, Vol.6, No.6 (Dec 2016)
}

\begin{abstract}
The degradation of water quality in Tunisia is mainly due to the overexploitation of groundwater, pollution and especially mismanagement in the different areas. Magnetic treatment methods can be used in the field of agriculture to alleviate salinity problems of irrigation. It is clear that the magnetic device influences the characteristics of limestone. On the other hand, there is variation in the physico-chemical characteristics of water which improves productivity and crop performance. The performance of irrigation by magnetized water is greater than irrigation by raw water. In this context, we examine the existence of the beneficial effects of the magnetic treatment of irrigation water on its quality and on the yield of the melon culture. As a result, a permanent magnet apparatus (Magneteau) installed on the irrigation line was used. The application of a magnetic field showed an influence on the water parameters, decreasing its electrical conductivity (EC) by 5.2\% and increasing its $p H$ by $5.6 \%$. In addition, the effect of this magnetic device showed an increase in melon cultivation of 39\%. Statistical analysis showed that our experimental results are very significant.
\end{abstract}

Keywords: Magnetic device, Irrigation water, Culture of Melon, Statistical analysis.

\section{Introduction}

In recent years, the effects of magnetic fields on water have been of interest to physicists, chemists and biologists (Parsons et al., 1997). Smirnov (2003) stated that water, as a conductor of electromagnetic waves, can receive signals emitted by magnetic forces and thus becomes the mediator between the source of magnetic field and the plant. These results are endorsed by Pang and Deng (2008) who added that the application of a magnetic field creates changes in the physical and chemical properties of water at microscopic and macroscopic scales. In addition, Cai et al. (2009) explained these changes by the formation of a large number of hydrogen bonds. Today, magnetic processing is of interest to several sectors of activity such as health, environment, industry, etc. In particular, we are targeting its applications in agriculture.

Some authors claim favorable effects of magnetism technology on the effects of water such as the removal of limestone deposits (Chibowski et al., 2003; Alimi et al., 2006) in water pipes, improved germination rate and the stimulation of growth (Shabrangi et al., 2009).

*Corresponding author: Anis Elaoud
It should be noted, however, that the application in agriculture of this magnetism technology can take place either by directly exposing organs of the plant (such as seeds) to the magnetic field (Florez et al., 2007), which is justified by the presence of properties Paramagnetic in the chloroplast, or via exposure of irrigation water to this magnetic field (Hozayn and Qados, 2010a). This improvement can be attributed to the formation of new protein bands (Hozayn and Qados, 2010b). On the other hand, Celik et al. (2008) and Shabrangi et al. (2009) reported that this physical treatment affects gene expression by increasing biological reactions such as protein synthesis.

Magnetic water treatment devices are environmentally friendly, competitively priced and no energy requirements (Hozyan and Qados, 2010a). However, little research is directed at improving the characteristics of the magnetic machine and optimizing the parameters for treatment against the salinity of irrigation water. Thus, magnetized water used for irrigation can improve water productivity (Maheshwari et al., 2009), thus conserving water supply for the future in light of the expected global water shortage. Alkhazan and Saddik (2010), have shown that a magnetic field can physically and chemically affect water. The physical and chemical 
properties for samples were measured, in addition to their bacterial content. In both cases of static and shaking, the magnitude of the magnetic flux is increased and the electrical conductivity (EC) is increased. Researchers observed that magnetized water helps in dissolving minerals and acids by a higher rate than unmagnetized water, in addition to dissolving oxygen and increasing the speed of chemical reactions (Moon and Chung, 2000).

Smirnov (2003) noticed that water can receive signals produced from magnetic forces that have a direct effect on living cells and their vital action. Clear inverse correlations between metallic pollutants concentrations and concentration-dependant magnetic characteristics are observed by Georgeaud et al. (1998) and Matasova et al. (2005). Krzemieniewski et al. (2004) revealed that the magnetization of tap water allows it to achieve its full oxygenation capacity.

The magnetized water used for irrigation can promote the development of the plant and increase its production (Dattatry and Vijaysinh, 2015). Taimourya et al. (2015) showed that the static magnetic field has positive effects such as stimulating growth and improving the production of cabbage (Brassica oleracea) of about $30 \%$.

Generally, literature reports show a possibility that this physical treatment of water can have beneficial effects on water productivity as well as on plant growth parameters, thus making water a less limiting factor for the production. Yet the explanations of the mechanism of action of this treatment remain hypothetical and restricted. It should be noted that research oriented in this context remains very limited.

In this context, our subject arises in order to study the effect of magnetic fields on the physical and chemical parameters of water in order to bring about the improvement of the quality of the water and also the yield of the crops.

\section{Materials and methods}

\subsection{Generality}

Our work has been done on a farm field at GrombaliaNabeul (Tunisia). The irrigation water used is a superficial well of salinity $2.6 \mathrm{~g} / \mathrm{l}$.

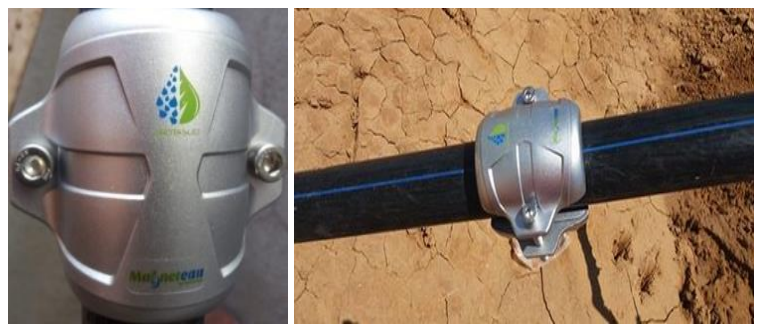

Fig.1 Magnetic device (Magneteau) mounted on the irrigation line

The study and analysis of the water was conducted within the Water Research and Technologies CenterBorj Cedria Tunisia.
The experimental device is in complete random block to three repetitions. In each block contains 10 test plants. In this work, the magnetic device (mark: Magneteau) is mounted on the irrigation line in order to obtain magnetized water (Figure1). The intensity of the magnetic field produced by the apparatus is $1.5 \mathrm{~T}$.

\subsection{Measurement of $\mathrm{pH}$ and Electrical Conductivity EC}

Conductivity and $\mathrm{pH}$ are measured directly using probes linked to the $\mathrm{pH}$ meter and a conductimeter. These two probes are connected to a recorder in order to see the variation of these two parameters during 4 successive days (Fig 2).

The electrical conductivity represents the conductance which is the inverse of the resistance that water opposes to the passage of an electric current when it is inserted in cell between two metal electrodes of $1 \mathrm{~cm}^{2}$ of surface and separated one of the other $1 \mathrm{~cm}$.

The conductivity unit is the Siemens per meter $(\mathrm{S} / \mathrm{m})$. It is proportional to the mineralization of water, the more water is rich in ionized mineral salts, the higher conductivity.

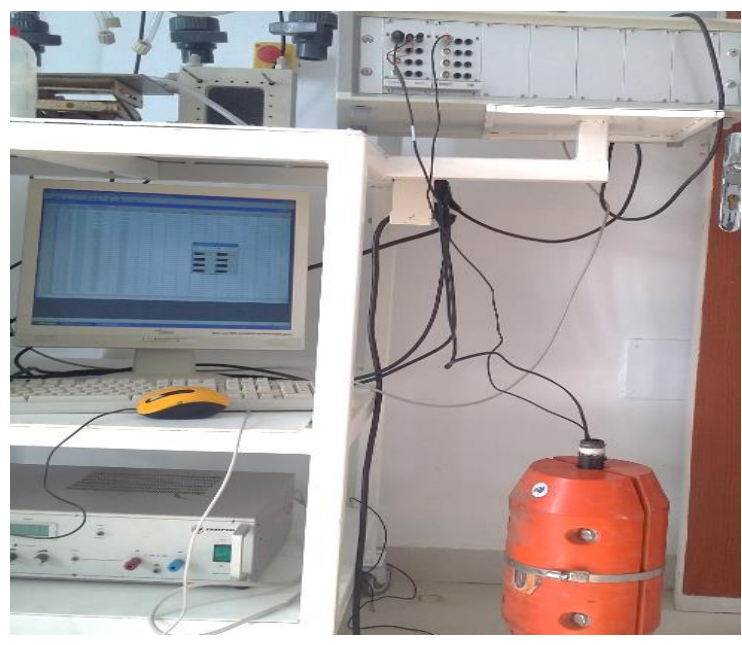

Fig.2Probes connected to the recorder

\subsection{Measurement of yield of melon culture}

The yield of the melon culture is measured in the three blocks. Two measured parts: the first part linked to the harvest of the crop irrigated by a raw water and the second part by a magnetized water. After three harvests, the effect of magnetized water on the melon harvest can be compared.

\subsection{Statistical Analysis}

The results data were submitted to an analysis of variance at a $5 \%$ significance level. The effects of the variables were studied by regression analysis. All statistical analyses were performed using the Excel specific program (Statistical). The analysis based on the coefficient of determination, the significance of 
regression coefficients. The significance of coefficients was estimated by student's t-test and p-values. The higher the level of the t-value and the lower the pvalue, the more significant is the coefficient (Khuri et al., 1987). The sign of each coefficient suggests the direction of the relationship. The elimination of insignificant variables gives more accurate forecasts according to Sonmez and Rowings (Sonmez et al., 1998). The $R^{2}$ have been widely used for model evaluation, these statistics are oversensitive to high extreme values and insensitive to additive and proportional differences between model predictions and measured data (Legates et al., 1999).

\section{Results and discussion}

The objective of this study is to value the influence of the magnetic device on water ( $\mathrm{EC}$ and $\mathrm{pH}$ ) and also on the yield of the melon culture.

The monitoring of the variation of the electrical conductivity and $\mathrm{pH}$ of the water samples of the well, after magnetic treatment and before magnetization, was carried out and followed for 4 days.

This work shows the EC decrease in magnetized water and the increase in $\mathrm{pH}$ during magnetic tracing. This variation depends on the time following the processing phenomenon before reaching the initial value.

The variation of the EC from 3801 to $3405 \mu \mathrm{s} / \mathrm{cm}$ and thereafter the return to the initial value. This decrease is estimated at $5.2 \%$. (Figure 1)

Concerning the $\mathrm{pH}$ : it is observed that it varies contrary to the EC. It increases from 7.15 to 7.58 and then returns to the initial value. In our case, the $\mathrm{pH}$ increase goes up more than $5.6 \%$ (Table 1). Our results show that the magnetization of water has a memory effect such that this treatment lasts about 3 days.
The yield of the harvest of the melon is carried out on 3 crops. Harvesting of the irrigated part with magnetized water shows a significant increase compared to the harvest of the irrigated part with raw water (not magnetized).

The treatment of water by a magnetic field, improves plant growth with a significant gain in production and yield. An increase in melon yield (39\%) is accompanied by magnetic treatment (Table 2).

The results of this study of the effect of magnetic devices on water and agricultural yield of melon are consistent with the literature on other crops such as lettuce, cabbage, melon and tomato (Lin and Yotvat, 1989). This improvement in yield is justified by better assimilation of fertilizers.

Sadeghipour and Aghaei (2013) admitted this last result, pointing out that the consistency of the magnetically treated water on the growth of the crow induce an improvement in the water and nutrient absorption capacities.

Our results are coherent with that of Taimourya et al. (2015), which showed the beneficial effect of magnetized water on the yield increase of cabbage.

We observe the high significance of these results with a regression $\mathrm{R}(0.99)$ (Table 3 ).

To test the significance of the regression analysis of variance (F-test) is performed according to the standard procedure. If the calculated $\mathrm{F}$ value is greater than the $\mathrm{F}$ critical value, there is a real relation between dependent and independent variables. This test follows an F-distribution with degree of freedom (d.o.f) $v=1$, so that the critical region will consist of a value exceeding $8.9127 \mathrm{E}-11$. The calculated $\mathrm{F}$-value $(\mathrm{F}=557.882182)$ is greater than the critical $\mathrm{F}$-value (8.9127E-11). As the Fisher F-value observed is much greater than the critical value $F$, which confirms the high significance of the work (Table 4).

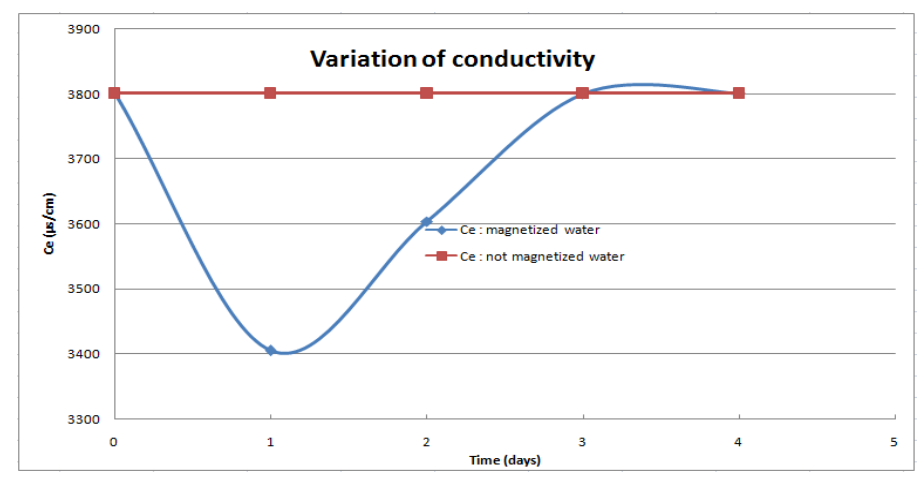

Fig. 3 Variation of conductivity

Table 1 Variation of conductivity and $\mathrm{pH}$

\begin{tabular}{ccccc}
\hline Day & EC* (Treated water) $^{*}$ & EC* $^{*}$ (Untreated water) & pH (treated water) & pH (Untreated water) \\
\hline 0 & 3801 & 3801 & 7,15 & 7,15 \\
1 & 3405 & 3801 & 7,58 & 7,15 \\
2 & 3604 & 3801 & 7,22 & 7,15 \\
3 & 3800 & 3801 & 7,15 & 7,15 \\
4 & 3801 & 3801 & 7,15 & 7,15 \\
\hline
\end{tabular}


Table 2 Yield of melon culture

\begin{tabular}{cccc}
\hline Culture of melon(10 plants) & Not magnetized & Magnetized & Variation \% \\
\hline First harvest & $7.200 \mathrm{~kg}$ & $9.000 \mathrm{~kg}$ & 25.0 \\
Second harvest & $9.400 \mathrm{~kg}$ & $14.000 \mathrm{~kg}$ & 48.9 \\
Third harvest & $10.100 \mathrm{~kg}$ & $14.200 \mathrm{~kg}$ & 40.6 \\
\hline Total & $26.700 \mathrm{~kg}$ & $37.200 \mathrm{~kg}$ & 39.3 \\
\hline
\end{tabular}

Table 3 Statistical regression

\begin{tabular}{cc}
\hline \multicolumn{2}{c}{ Statisticalregression } \\
\hline Multiple determination coefficient & 0.99028472 \\
Coefficient of determination $\mathrm{R}^{2}$ & 0.98066383 \\
Standard Error & 0.89008156 \\
Observations & 13 \\
\hline
\end{tabular}

Table 4 Analysis of variance

\begin{tabular}{cccccc}
\hline & $\begin{array}{c}\text { Degree of } \\
\text { freedom }\end{array}$ & $\begin{array}{c}\text { Sum of } \\
\text { squares }\end{array}$ & $\begin{array}{c}\text { Average of } \\
\text { squares }\end{array}$ & F & $\begin{array}{c}\text { Critical } \\
\text { value of F }\end{array}$ \\
\hline Regression & 1 & 441.97947 & 441.97947 & 557.88218 & $8.91 \mathrm{E}-11$ \\
Residues & 11 & 8.714697 & 0.7922452 & & \\
Total & 12 & 450.69417 & & & \\
\hline
\end{tabular}

\section{Conclusion}

The application of a magnetic field showed an influence on the physical parameters of the raw water, decreasing electrical conductivity (EC) of $5.2 \%$ and increasing $\mathrm{pH}$ of $5.6 \%$.

Water treated with increased yield (39\%) of production. Statistical analysis showed a high significance and the results gave a regression R (0.99). This new technology paves the way for specific treatments using the electromagnetic properties of water, the knowledge of which requires further investigation.

There is also a need to better understand the direct effects of magnetic technology on the plant.

\section{Acknowledgment}

This study was funded by Laboratory of Natural Treatment Water-Water Research and Technologies Center-Borj Cedria, Tunisia. Our thanks to Professor Ben Amor M. for his scientific and financial encouragement.

\section{References}

Alimi F., Tlili M., Amor M., Gabrielli C. and Maurin G. (2006).Influence of Magnetic Field on Calcium Carbonate Precipitation.Desalination 206: 163- 168.

Alkhazan M. and SaddiqA. (2010). The effect of magnetic field on the physical, chemical and microbiological properties of the lake water in Saudi Arabia. Journal of Evolutionary Biology Research Vol. 2 (1), pp. 7-14.

Cai R., Yang H., He J. et Zhu W. (2009). The Effects of Magnetic Fields on Water Molecular Hydrogen Bonds. Journal of Molecular Structure 938:15-19.

Çelik Ö., Atak Ç., Rzakulieva A. (2008). Stimulation of Rapid Regeneration by a Magnetic Field in Paulownia Node Cultures.Journal of Central Europ. Agric. 9 (2): 297 - 303.
Chibowski E, Holysz L, Szczes A, Chibowski M (2003). Precipitation of calcium carbonate from magnetically treated sodium carbonate solution. Colloids Surf. A, 225: 63-73.

Florez M., Carbonell M.V. et Martinez E. (2007). Exposure of Maize Seeds to Stationary Magnetic Fields: Effects on Germination and Early Growth. Environ. Exp. Bot. 59:6875.

Georgeaud V.M., Rochette P., Ambrosi J.P., Vandamme D. and Williamson D. (1998). Relationship between heavy metals and magnetic properties in a large polluted catchment: The Etang de Berre (south of France). Phys. Chem. Earth, 22: 211-214.

Hozayn M. and Qados A. (2010 a). Irrigation With Magnetized Water Enhances Growth, Chemical Constituent and Yield of Chickpea (Cicerarietinum L.). Agriculture and Biology Journal of North America 1(4): 671-676.

Hozayn M. and Qados A. (2010 b).Magnetic Water Technology, a Novel Tool to Increase Growth, Yield and Chemical Constituents of Lentil (Lens esculenta) Under Greenhouse Condition. American-Eurasian J. Agric and Environ. Sci. 7(4): 457-462.

Krzemieniewski M., Dbowski M., Janczukowicz W. and Pesta J. (2004).Effect of the Constant Magnetic Field on the Composition of Dairy Wastewater and Domestic Sewage. Polish J. Environ. Stud., 13: 45-53.

Khuri A.I., Cornell J.A. (1987). Response Surfaces, Marcel Dekker, New York.

Legates D.R., McCabe G.J. (1999).Evaluating the use of 'goodness-of-fit' measures in hydrologic and hydroclimatic model validation. Water Resour. Res. 35: 233-241.

Lin I.J. etYotvat J. (1989). Treatment of drinking and irrigation water in animal and plant husbandry by electromagnetic technology. Magnetic separation news 2:179-187.

Maheshwari L. and Grewal H.S. (2009). Magnetic treatment of irrigation water: Its effects on vegetable crop yield and water productivity. Agricultural Water Management 96 : 1229-1236.

Matasova G.G., Kazansky A.Y., Bortnikova S.B., and Airijants A.A. (2005). The use of magnetic methods in an 
environmental study of areas polluted with non-magnetic wastes of the mining industry (Sal air region, Western Siberia, Russia). Geochemistry: Explor. Environ. Analy., 10: 75-89.

Moon J.D., Chung H.S. (2000). Acceleration of germination of tomato seed by applying an electric and magnetic field. J. Electro-Statistics, 48:103-114.

Sadeghipour 0. and Aghaei P. (2013).Improving the Growth of Cowpea (VignaUnguiculata L. Walp) by Magnetized Water.Journal of Bio.andEnv. 3: 37-43.

Pang X.F. and Deng B. (2008). The Change of Macroscopic Features and Microscopic Structures of Water Under Influence of Magnetic Field. Physica B 403: 3571- 3577.

Parsons S. A., Judd S. J., Stephenson T., Udol S. and Wang B.L. (1997).Magnetically augmented water treatment. Institution of Chemical Engineers, Trans IChemE, Vol 75, Part B.
Smirnov J.V. (2003). BioMagnetic hydrology.The Effect of a Specially Modified Electromagnetic Field on the Molecular Structure of Liquid Water.Global Quantec. Inc., U.S.A, pp. 122-125

Sonmez R. and Rowings J. (1998).Construction labor productivity modeling with neuronal networks, Journal of construction engineering and management, Vol.124, N6. P. 498-504

Shabrangi A. and Majd A. (2009).Effect of Magnetic Fields on Growth and Antioxidant Systems in Agricultural Plants. PIERS Proceedings, Beijing, (China), March, 23-27.

Taimourya H., Bourarach E.H., El Harif A., Hassanain N., Masmoudi L., Baamal L., and Oussible M. (2015).Évaluation de la productivité du chou pommé (Brassicaoleracea), sous l'effet de l'irrigation avec une eau traitée magnétiquement, dans la région de Casablanca (Maroc). Rev. Mar. Sci. Agron. Vét. 3 (2):27-36. 